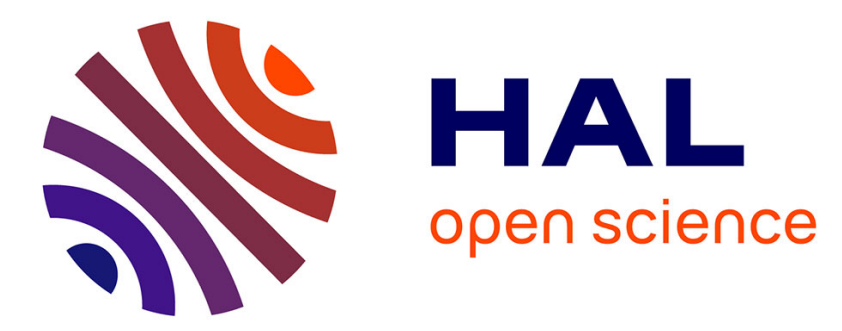

\title{
The role of surface friction in downslope windstorms
} Evelyne Richard, Patrick Mascart, Everett C. Nickerson

\section{To cite this version:}

Evelyne Richard, Patrick Mascart, Everett C. Nickerson. The role of surface friction in downslope windstorms. Journal of Applied Meteorology, 1989. hal-01986123

\section{HAL Id: hal-01986123 \\ https://hal.uca.fr/hal-01986123}

Submitted on 3 Dec 2021

HAL is a multi-disciplinary open access archive for the deposit and dissemination of scientific research documents, whether they are published or not. The documents may come from teaching and research institutions in France or abroad, or from public or private research centers.

$$
\text { Copyright }
$$

L'archive ouverte pluridisciplinaire HAL, est destinée au dépôt et à la diffusion de documents scientifiques de niveau recherche, publiés ou non, émanant des établissements d'enseignement et de recherche français ou étrangers, des laboratoires publics ou privés. 


\title{
The Role of Surface Friction in Downslope Windstorms
}

\author{
EVELYNE RICHARD \\ Laboratoire Associé de Météorologie Physique, Université Blaise Pascal, Aubière, France \\ PATRICK MASCART \\ Laboratoire Associé de Météorologie Physique, Université Blaise Pascal, Aubière, France \\ EVERETT C. NiCKERSON \\ National Oceanic and Atmospheric Administration, PROFS, Boulder, Colorado
}

(Manuscript received 30 January 1988, in final form 8 August 1988)

\begin{abstract}
Numerical simulations of the 11 January 1972 windstorm in Boulder, Colorado, were carried out using a hydrostatic model with a turbulent kinetic energy parameterization to investigate the role of frictional effects in the development of nonlinear mountain waves. Sensitivity tests to the roughness length specification and to the turbulent mixing and dissipation length formulations show that surface friction delays the onset of the strong surface winds and also prevents the downstream propagation of the zone of maximum windspeed. Shear production within convectively stable regions is the dominant mechanism for the production of the turbulent kinetic energy. Moreover, these results are consistent with the hypothesis that a hydrostatic amplification mechanism is capable of accounting for the development of strong downslope winds.
\end{abstract}

\section{Introduction}

Although mountain lee waves have been studied extensively for the last $40 \mathrm{yr}$, the influence of surface friction effects on the dynamics of these waves has received little attention. This lack of interest is due partly to the qualitative success of frictionless simulation in reproducing lee wave flows and partly to the difficulty of introducing surface friction in theoretical models.

In order to investigate the role of such effects, numerical simulations of nonlinear mountain flows were carried out with a two-dimensional version of a hydrostatic model including a turbulent kinetic energy (TKE) parameterization to model the friction in the boundary layer and in shear layers at higher levels. In a previous paper, Nickerson et al. (1986) compared the simulated quasi-linear and nonlinear hydrostatic waves with analytical solutions (Queney 1948) and results from other numerical studies (Klemp and Lilly 1978; Mahrer and Pielke 1978; Durran and Klemp 1983). In the present paper, all the simulations were performed using the Grand Junction, Colorado, sounding of 11 January 1972 . This situation was chosen because it is one of the most spectacular cases of down-

Corresponding author address: Dr. Evelyne Richard, Laboratoire Associé de Météorologie Physique, Université Blaise Pascal, BP45, 63177 Aubiere, France. slope windstorms to be observed and numerically well documented.

The observational data have been discussed many times in the past years (Lilly and Zipser 1972; Lilly and Kennedy 1973; Klemp and Lilly 1975, 1978; Lilly 1978; Smith 1977). The observations show (see for instance Figs. 7 and 9 in Lilly 1978) that the flow is highly nonlinear since the vertical deflection of the isentropes is approximately three times the maximum height of the topography. Oscillations of the isentropes to the lee of the peak in the low levels indicate also the presence of trapped lee waves. Very strong surface winds $\left(55 \mathrm{~m} \mathrm{~s}^{-1}\right)$ were recorded in Boulder.

Three different mechanisms have been proposed to account for the development of these strong downslope winds. One mechanism is based on hydraulics theory: strong winds will occur along the lee slope when the fluid undergoes a transition from subcritical flow upstream to supercritical flow over the mountain (Smith 1985; Durran 1986; Durran and Klemp 1987). A second mechanism is based on linear theory: Klemp and Lilly (1975) suggested that strong downslope winds occur when the atmosphere has a multilayer structure which produces an optimal superposition of upwardand downward-propagating waves. A third mechanism, proposed by Clark and Peltier (1977), is based on numerical simulations. Clark and Peltier suggested that large-amplitude waves and downslope winds are pro- 
duced after a developing wave breaks; the energy in the upward propagating wave is trapped beneath its own level of "supercritical steepening," producing a substantial increase in the wave amplitude.

In section 2, we begin by describing the numerical model and the turbulent kinetic energy parameterization. Section 3 provides a comparison of two simulations of the Boulder windstorm with and without frictional effects. The sensitivity to the turbulent mixing and dissipation lengths as well as to the roughness length specification is examined in section 4 . Section 5 contains the conclusions.

\section{Model description}

\section{a. Model equations}

The simulations presented here were obtained using the hydrostatic model described by Nickerson et al. (1986). The model was adapted to calculate two-dimensional airflow over an infinitely long mountain barrier. The Coriolis term was neglected. In the absence of moisture, the equations are the following:

$$
\begin{gathered}
\frac{\partial \pi u}{\partial t}=-\frac{\partial \pi u u}{\partial x}-\frac{1}{\sigma^{\prime}} \frac{\partial \pi u \sigma^{\prime} \dot{\nu}}{\partial \nu} \\
+(\phi-R T) \frac{\partial \pi}{\partial x}-\frac{\partial \pi \phi}{\partial x}+F_{u}+D_{u}, \\
\frac{\partial \pi H}{\partial t}=-\frac{\partial \pi H u}{\partial x}-\frac{1}{\sigma^{\prime}} \frac{\partial \pi H \sigma^{\prime} \nu}{\partial \nu}+F_{l l}+D_{l l} \\
\frac{\partial \pi}{\partial t}=\int_{0}^{1} \frac{\partial \pi u}{\partial x} \sigma^{\prime} d \nu \\
\dot{\nu}=-\frac{1}{\pi \sigma^{\prime}} \int_{0}^{\nu} \sigma^{\prime}\left(\frac{\partial \pi}{\partial t}+\frac{\partial \pi u}{\partial x}\right) d \nu \\
\frac{\partial \phi}{\partial \hat{p}}=-c_{p} \theta .
\end{gathered}
$$

All symbols are defined in the Appendix. Equations (1) and (2) are respectively momentum and thermodynamic equations. Equation (3) is the continuity equation, and (5) is the hydrostatic equation. The vertical velocity calculation is given by (4).

Equations are written in a terrain-following coordinate system. The vertical coordinate $\nu$ is related to the classical $\sigma$ coordinate by $\sigma=\nu+0.9 \nu^{2}-0.9 \nu^{3}$. This choice of vertical coordinate allows a higher resolution in the low levels while keeping a constant vertical spacing in the $\nu$ system.

An additional equation for the mean turbulent kinetic energy, defined by $e=0.5\left(\bar{u}^{\prime}+\bar{w}^{\prime}\right)$, completes the above system:

$$
\begin{aligned}
\frac{\partial \pi e}{\partial t}= & -\frac{\partial \pi e u}{\partial x}-\frac{1}{\sigma^{\prime}} \frac{\partial \pi e \sigma^{\prime} \nu}{\partial \nu}+\pi K_{u}\left(B \frac{\partial u}{\partial \nu}\right)^{2} \\
& -\frac{g}{\theta_{0}} \pi K_{\theta} B \frac{\partial \theta}{\partial \nu}-0.125 \pi \frac{e^{3 / 2}}{l_{e}}+F_{e}+D_{e} .
\end{aligned}
$$

The first terms on the right-hand side of Eq. (6) describe respectively horizontal and vertical advection, vertical diffusion, shear production, buoyancy production and viscous dissipation.

The terms $D$ and $F$ in (1), (2), and (6) denote respectively the horizontal diffusion terms (fourth-order operator) and the turbulent mixing terms. Turbulent fluxes are expressed through an eddy diffusivity assumption, which yields

$$
\begin{gathered}
F_{u}=B \frac{\partial}{\partial \nu}\left(B K_{u} \frac{\partial \pi u}{\partial \nu}\right), \\
F_{1 I}=B \frac{\partial}{\partial \nu}\left(B K_{\theta} \frac{\partial \pi H}{\partial \nu}\right), \\
F_{e}=B \frac{\partial}{\partial \nu}\left(B K_{e} \frac{\partial \pi e}{\partial \nu}\right),
\end{gathered}
$$

with

$$
B=-\frac{g p}{R T \sigma^{\prime}} .
$$

The exchange coefficients for momentum $K_{u}$, heat $K_{\theta}$, and turbulent kinetic energy $K_{e}$ are functions of the turbulent kinetic energy. They are computed as follows:

$$
\begin{aligned}
K_{u} & =0.5 l_{k} \sqrt{e}, \\
K_{\theta} & =1.35 K_{u}, \\
K_{e} & =1.3 K_{u} .
\end{aligned}
$$

In order to solve the problem completely, the mixing and dissipation lengths $l_{k}$ and $l_{\epsilon}$ must be specified. The mixing length $l_{k}$ is given by

$$
\frac{1}{l_{k}}=\frac{1}{k\left(z-z_{s}\right)}+\frac{C K 1}{H}+\frac{C K 5}{l_{s}},
$$

where $z_{s}$ is the ground elevation and $H$ the depth of the convective instability; $l_{s}$ is given by

$$
\frac{1}{l_{s}}= \begin{cases}0 & \text { if } \frac{\partial \theta}{\partial z} \leqslant 0 \\ \left(\frac{g}{\theta_{0}} \frac{\partial \theta}{\partial z} \frac{1}{e}\right)^{1 / 2} & \text { otherwise. }\end{cases}
$$

The dissipation length $l_{\varepsilon}$ is computed according to

$$
\frac{1}{l_{\epsilon}}=\frac{1}{k\left(z-z_{s}\right)}+\frac{C E 1}{H}+\frac{C E 5}{l_{s}} ;
$$

$C K 1, C K 5, C E 1$, and $C E 5$ are empirical constants. 


$$
\begin{aligned}
& C K 1=C E 1=15 \\
& C K 5=C E 5=1.5 .
\end{aligned}
$$

The choice of the mixing and dissipation lengths formulation is discussed in section 4a. Further details about this parameterization originating from planetary boundary layer studies may be found in Mahfouf et al. (1987) and in Therry and Lacarrère (1983).

At the ground, the surface layer fluxes of momentum and heat are based on the work of Businger (1973), using the formulation of Louis (1979).

\section{b. Initial conditions and boundary conditions}

The computational domain contains 52 horizontal grid points and 61 vertical grid levels. The grid intervals are $\Delta x=10 \mathrm{~km}$ and $\Delta \nu=1 / 60$. The first vertical level is located at $7 \mathrm{~m}$ above the ground. The time step is $10 \mathrm{~s}$.

The lateral boundary conditions are Davies-type boundary conditions (Davies 1983), where $u, H$, and $\pi$ are relaxed toward their initial values. The top boundary condition is $i=0$, which is clearly a reflective condition. However, reflections from the top boundary can be virtually eliminated by including an absorbing layer at the top of the model in which the damping increases gradually as a function of height. This absorbing layer occupies the top 10 levels and starts at $12 \mathrm{~km}$ above the ground.

At the bottom, the mountain contour is specified by

$$
z_{s}(x)=\frac{h}{1+\frac{x^{2}}{a^{2}}}+1700,
$$

where $h=2000 \mathrm{~m}$ and $a=20 \mathrm{~km}$. When frictional effects are omitted, a free-slip boundary condition is assumed at the lower boundary.

The initial wind and temperature profiles are shown in Fig. 1. These profiles are from the Grand Junction sounding upstream of Boulder on 11 January 1972 and were taken from Peltier and Clark (1979).

\section{Results}

\section{a. Comparison with a free-slip simulation}

Two simulations were performed. In the first, no surface fluxes were allowed and a free-slip surface boundary condition was assumed for $u$ and $\theta$. In the second, the surface layer was assumed to be neutral (zero surface heat flux) with a uniform roughness length of $20 \mathrm{~cm}$.

A series of time slices through the evolving wind field superimposed on the potential temperature field for the first simulation between 3 and $8 \mathrm{~h}$ of model time are shown in Fig. 2. Only the central portion of the computational domain is shown in the figures. The tropopause is beginning to fall immediately over the
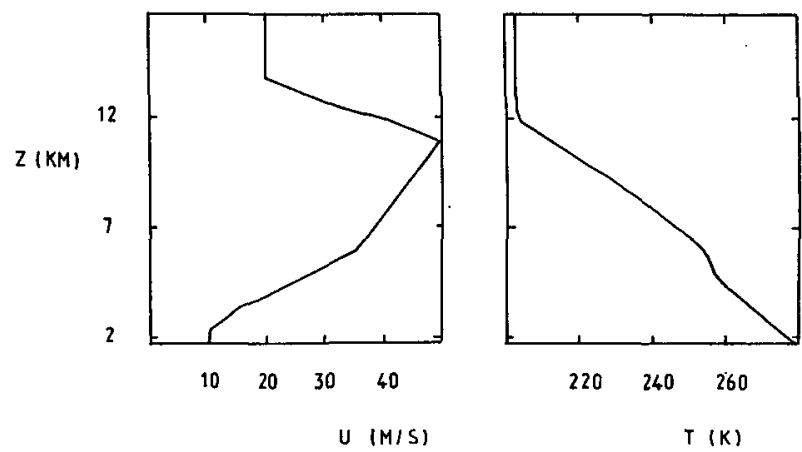

FIG. 1. Initial wind and temperature profiles.

crest of the mountain, and the magnitude of the downward deflection of the $320 \mathrm{~K}$ isentrope increases continuously. A high maximum horizontal wind is found in the low level to the lee of the peak, and the region of strongest surface wind migrates down to the lee slope during the course of the simulation. When the area of maximum wind speed reaches the bottom of the lee slope, the wind speed stops increasing but the area of maximum wind speed enlarges in the downwind direction.

Although the hydrostatic approximation precludes the simulation of the trapped lee waves at lower levels, our results are quite similar to those obtained by Peltier and Clark (1979) and Durran (1986) when compared at the same nondimensional time.

The results of the second simulation have been plotted in Fig. 3; the time series shown is now between 5 and $10 \mathrm{~h}$ of model time. The effect of surface friction is first to delay the development of the strong-wind area along the lee slope, which appears now after $6 \mathrm{~h}$. In the first simulation it occurred after only $4 \mathrm{~h}$. Another major difference between the two runs is that in the simulation with surface friction the overall jumplike structure remains stationary instead of propagating downstream. This makes the second simulation qualitatively more realistic than the first one. When the steady state is established, simulation results are in good agreement with the data: the location and intensity of the maximum wind speed as well as the magnitude of the isentropes' deflection are quite consistent with the observations.

The surface pressure drag across the mountain, defined by $D=\int_{0}^{L} \pi \frac{\partial z_{s}}{\partial x} d x$, where $L$ is the length of the computational domain, can be used as a measure of the strength of the wave response. The time-dependent development of the pressure drag across is shown in Fig. 4 for both simulations. The drag amplification occurs more slowly in the second simulation and the steady value is slightly weaker. Surface effect mainly delays the amplification mechanism but also slightly reduces it. 
3h

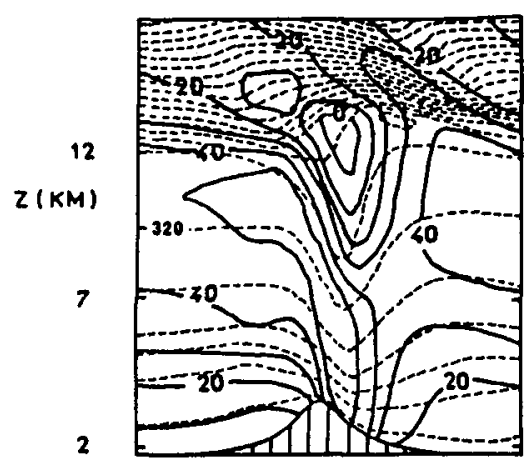

$\mathbf{5 h}$

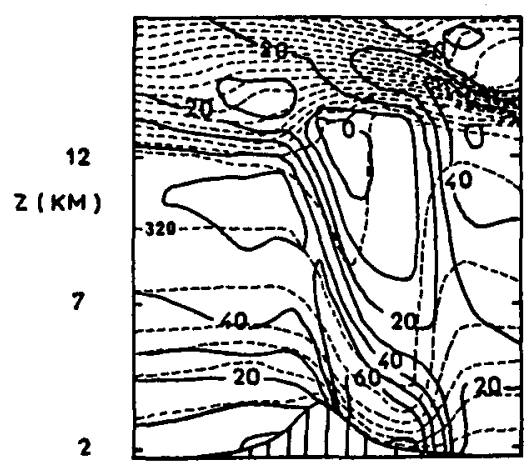

7h

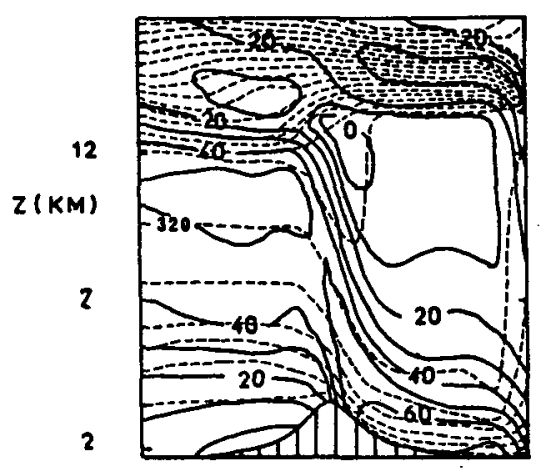

$4 h$

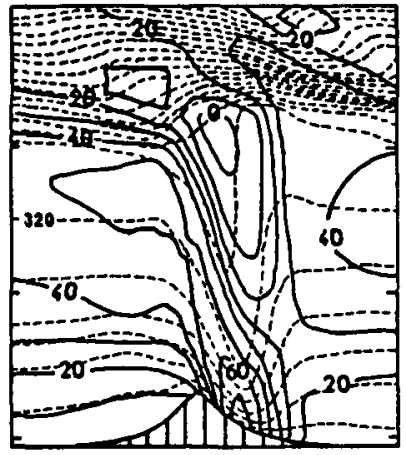

12

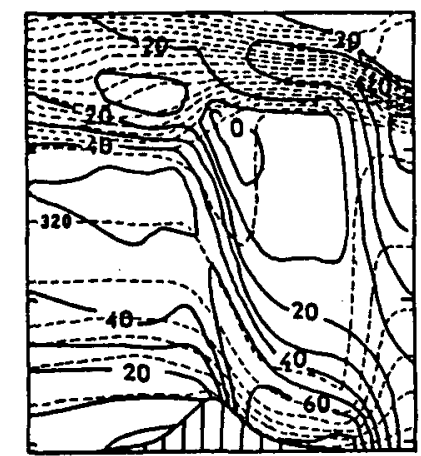

6h

$8 \mathbf{h}$

12

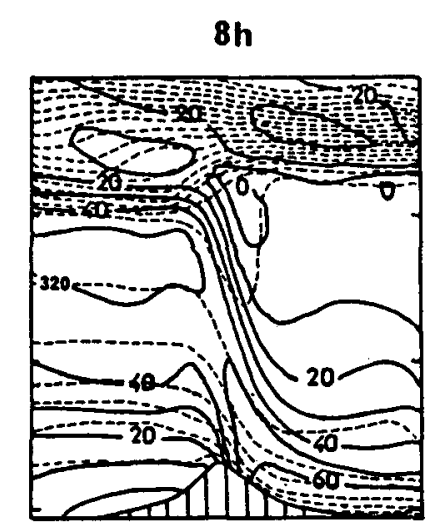

2

$50 \mathrm{~km}$

FuG. 2. Vertical cross sections of the wind field superimposed on the potential temperature field between 3 and $8 \mathrm{~h}$ of integration for the free-slip simulation. Isentropes are drawn every 5 $\mathrm{K}$, and only the $320-\mathrm{K}$ isentrope is labeled.

\section{b. Structure of the predicted TKE field}

Turbulence is another point of possible comparison between observations and simulations. Lilly (1978) examined extensively the distribution and intensity of turbulence for the 11 January 1972 windstorm. He reported the presence of two distinct zones of turbulence. The first one was near the ground, above the lee 

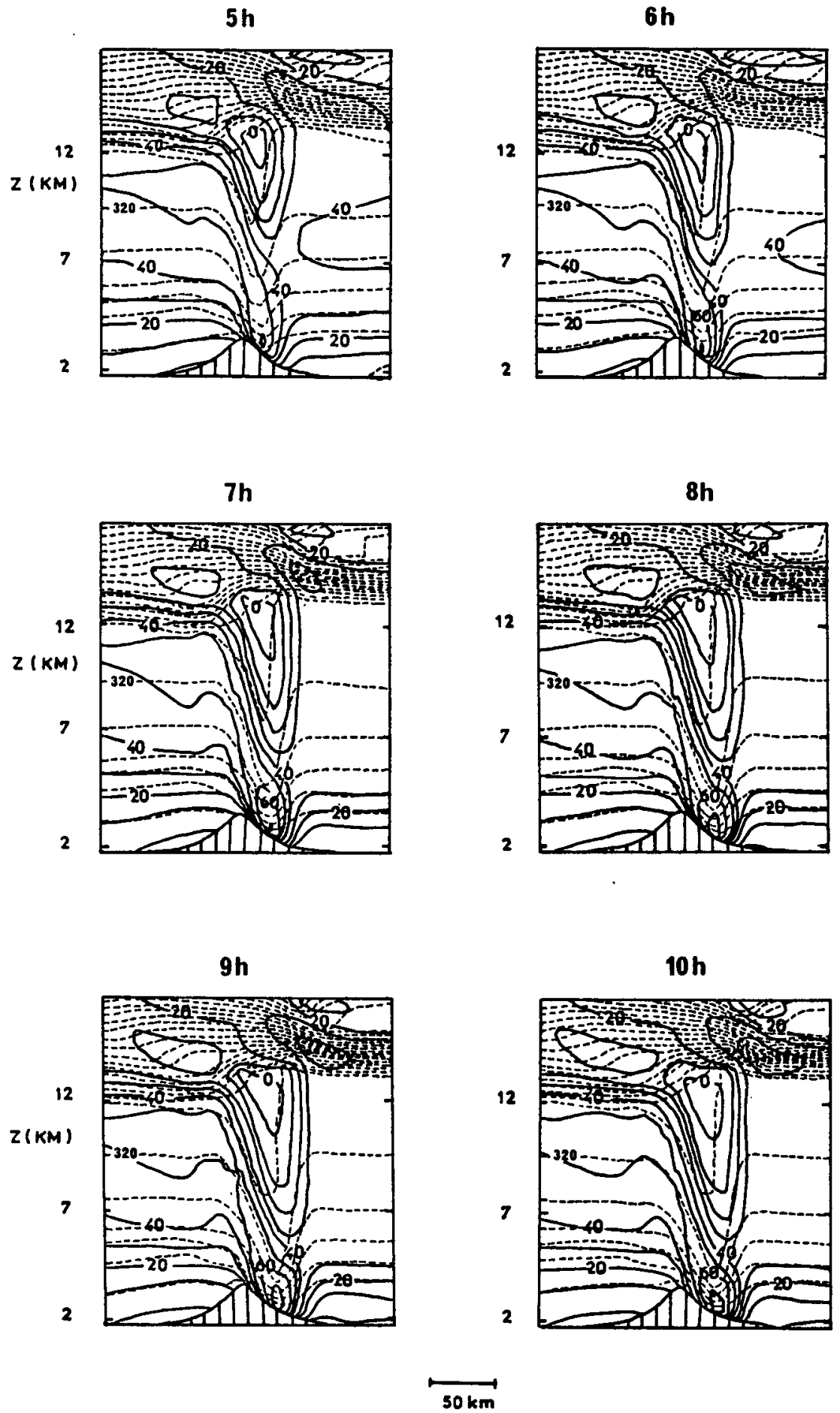

FlG. 3. Vertical cross sections of the wind field superimposed on the potential temperature field between 5 and $10 \mathrm{~h}$ of integration for the simulation with friction. Isentropes are drawn every $5 \mathrm{~K}$, and only the $320-\mathrm{K}$ isentrope is labeled.

slope, with a depth of 2 to $3 \mathrm{~km}$. A second separate region of intense turbulence was found in the midtroposphere, a few kilometers downstream of the crest of the mountain in the trough of the downstream wave.
More precisely, turbulence was recorded by instrumented aircraft at three flight levels 6,9 , and $12 \mathrm{~km}$ above sea level. The turbulence was very intense at the $6 \mathrm{~km}$ level over a horizontal distance of $15 \mathrm{~km}$. The 


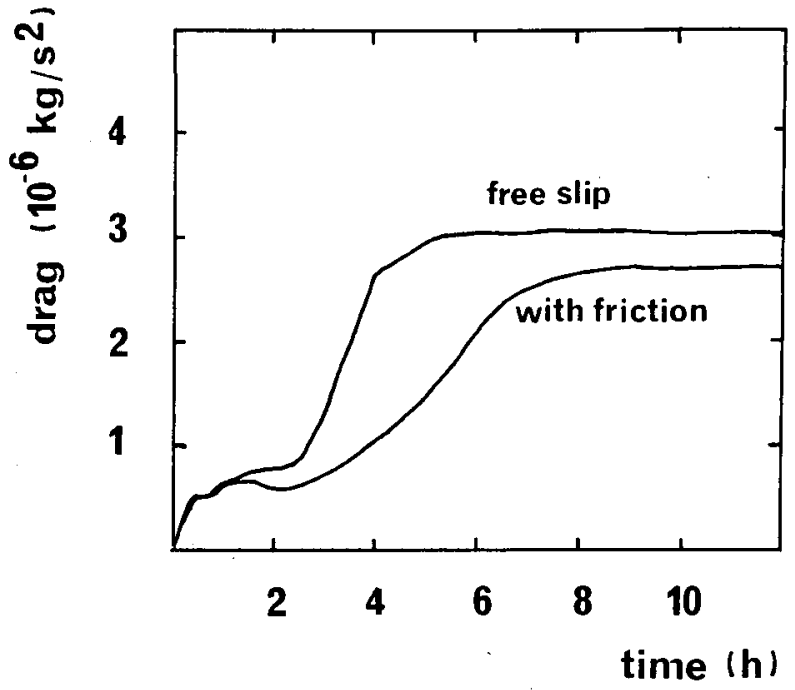

FJG. 4. Time evolutions of the surface pressure drag for the free-slip simulation and for the simulation with friction.

turbulence was much weaker at the 9 and $12 \mathrm{~km}$ levels but existed over longer distances.

As seen in Fig. 5, the model was able to reproduce these features. Figure $5 \mathrm{~b}$ shows the details of the low level turbulence zone above the lee slope of the mountain. The maximum value of the midtropospheric turbulence predicted by the model reaches $117 \mathrm{~m}^{2} \mathrm{~s}^{-2}$, whereas Lilly's analysis gives a value of $150 \mathrm{~m}^{2} \mathrm{~s}^{-2}$ for the 6-km level.

Examination of the different terms of the turbulent kinetic energy equation (shown in Fig. 6) reveals that for the midtropospheric turbulence the dominant production term is the shear. The center of production is found at $6 \mathrm{~km}$ above sea level, in the lower part of the turbulent zone. The buoyancy production term is smaller and mainly negative, indicating that turbulence develops in a region of stable stratification. The only positive values are weak and found in the upper part of the breaking wave. The next important term is vertical transport, carrying aloft (up to the tropopause) the turbulent energy produced at lower levels. Horizontal transport is also important but more localized. The role of turbulent diffusion is secondary. Turbulent diffusion is significant only in the region of maximum TKE production but is smaller than the vertical transport and works against it. Finally, the turbulence intensity is regulated by the dissipation term, which is the strongest negative contribution to the budget. These results are in fair agreement with Lilly's analysis; although the quantitative values are slightly weaker in the simulation than in the observations, the relative contributions of wind shear production, buoyancy production, advection, and dissipation terms are approximately the same for both experimental data and numerical computations (see Table 1 in Lilly 1978).

\section{Sensitivity tests}

\section{a. Mixing length}

A crucial point for TKE models is the choice of the characteristic lengths $l_{k}$ and $l_{\epsilon}$ in Eq. (3). A first step is the Blackadar (1962) formulation, which is assumed to describe accurately the neutral regime of the surface layer near the ground:

$$
\frac{1}{l}=\frac{1}{k\left(z-z_{s}\right)}+\frac{1}{l_{\infty}}
$$

where $l_{\infty}$ is an asymptotic value of $l$ far from the boundary, which can take several forms. Since most of the formulations proposed for $l_{\infty}$ are far beyond their domain of validity in the present case, one is led to resort to very simple formulations for $l_{\alpha}$. Because it is considered desirable to use smaller characteristic lengths under stable stratification and larger ones under convective conditions, it was decided to use two different formulations according to the local stratification. In case of stable local stratification $\left(\frac{\partial \theta}{\partial z}>0\right)$, one closely follows the André et al. (1978) proposition and determines $l_{k_{\alpha}}$ and $l_{\epsilon_{\alpha}}$ from the turbulent kinetic energy value and the Brunt-Väisälä frequency:

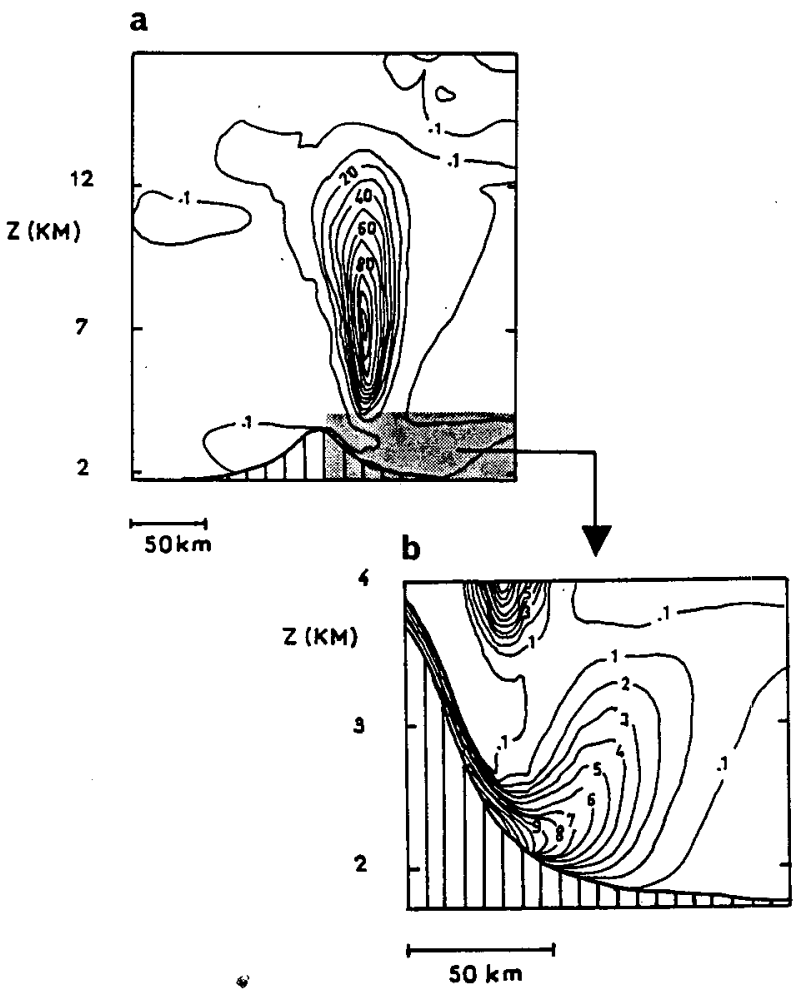

FIG. 5. (a) Vertical cross section of the turbulent kinetic energy field (in $\mathrm{m}^{2} \mathrm{~s}^{-2}$ ) after $12 \mathrm{~h}$ of integration for the simulation with friction. (b) Close-up view of the shaded area. 


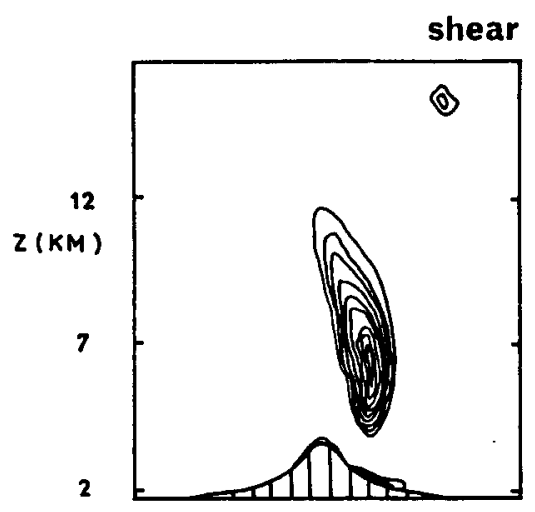

buoyancy
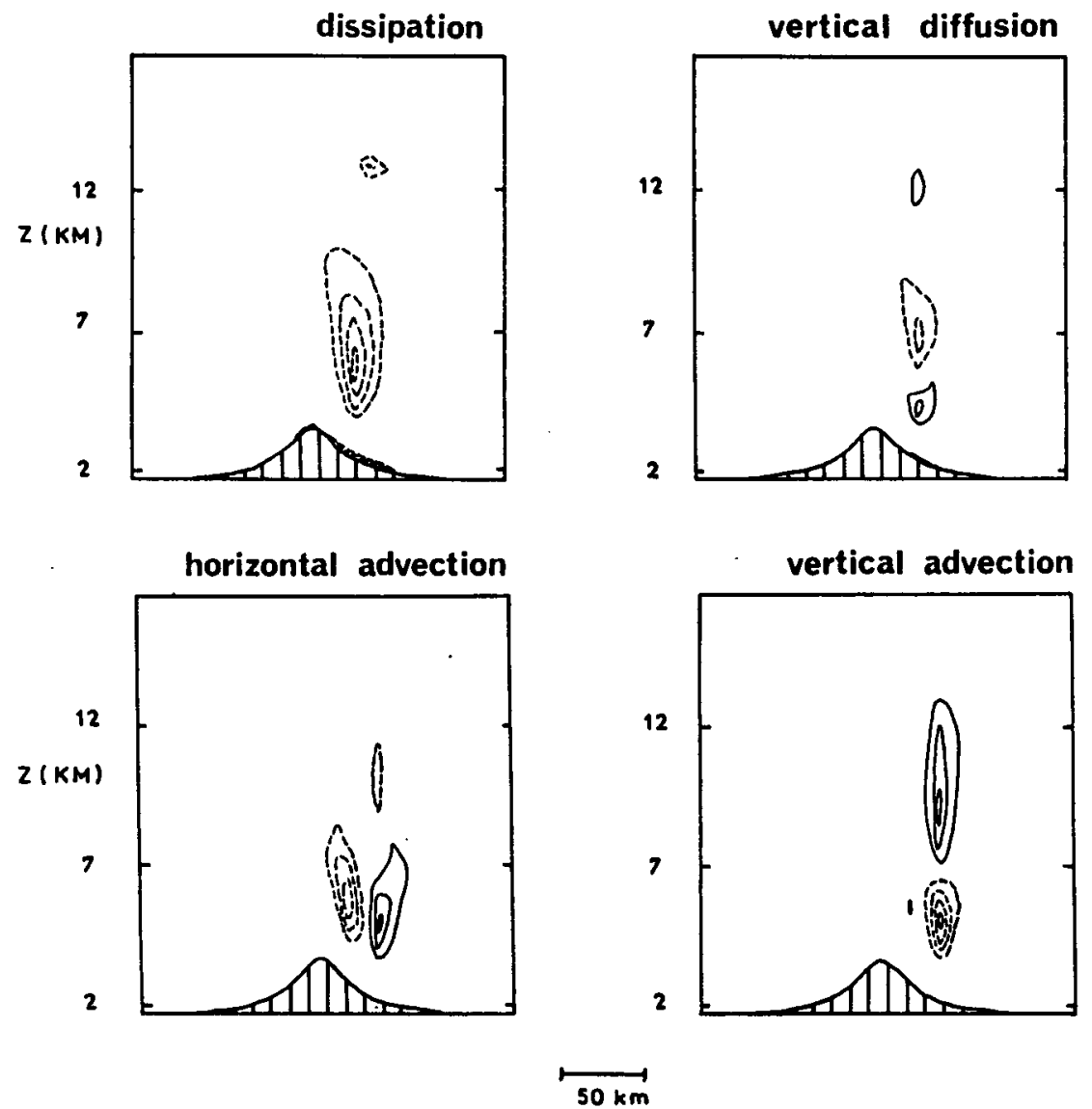

FlG. 6. Turbulent kinetic energy budget after $12 \mathrm{~h}$ of integration for the simulation with friction. The contours are drawn every $500 \mathrm{~cm}^{2} \mathrm{~s}^{-3}$ starting at $500 \mathrm{~cm}^{2} \mathrm{~s}^{-3}$ for the positive values (solid line) and at $-500 \mathrm{~cm}^{2} \mathrm{~s}^{-3}$ for the negative values (dashed line).

$\frac{1}{l_{\epsilon_{\alpha}}}=\frac{C E 5}{e^{0.5} N^{-1}}$ and $\frac{1}{l_{k_{\alpha}}}=\frac{C K 5}{e^{0.5} N^{-1}}$ if $\frac{\partial \theta}{\partial z}>0$.

In the case of convective instability $\left(\frac{\partial \theta}{\partial z}<0\right.$, i.e., wave breaking ), we first determine the depth of the unstable layer $H$, and make the assumption that the characteristic lengths $l_{k_{\alpha}}$ and $l_{\epsilon_{\alpha}}$ are proportional to $H$, which gives a rough estimate of the largest eddy size:

$$
\frac{1}{l_{\epsilon_{\alpha}}}=\frac{C E 1}{H} \text { and } \frac{1}{l_{k_{\alpha}}}=\frac{C K 1}{H}, \text { if } \frac{\partial \theta}{\partial z}<0 .
$$


TABLE 1 . Surface conditions and TKE model characteristics for the sensitivity tests.

\begin{tabular}{ccccccc}
\hline \hline Sim. no & Surface condition & $C E 1$ & $C E 5$ & $C K 1$ & $C K 5$ & $\mathrm{Ri}_{c}$ \\
\hline 1 & free slip & 15. & 1.5 & 15. & 1.5 & 0.52 \\
2 & free slip & 15. & 1.5 & 15. & 3.0 & 0.40 \\
3 & friction & 15. & 1.5 & 15. & 1.5 & 0.52 \\
4 & friction & 7.5 & 1.5 & 1.5 & 0.52 & 0.40 \\
5 & friction & 15. & 1.5 & 15. & 3.0 & 3.0 \\
6 & friction & 15. & 3.0 & 15. & 0.27 \\
\hline
\end{tabular}

Of course, the above parameterizations of $l_{\mathrm{f}}$ and $l_{k}$ are quite crude and, owing to the lack of both experimental and theoretical support that is valid in such severe conditions, it is necessary to evaluate the sensitivity of our results to variations of the constants $C E 1, C K 1, C E 5$, and $C K 5$. Six simulations were performed to investigate the sensitivity to these variations. The values used in each simulation are listed in Table 1 . This table also shows the value of the critical Richardson number $\mathbf{R i}_{c}$, which is the maximum Richardson number sustainable by the turbulence before collapsing under strongly stable conditions; $\mathrm{Ri}_{c}$ can be computed from the TKE equation rate as following (Therry and Lacarrére 1983):

$$
\mathrm{Ri}_{c}=\frac{1}{1.35+\frac{0.125}{0.5} C E 5 \times C K 5}
$$

Two simulations were performed with a free-slip surface condition and four with surface friction. The time evolutions of the surface pressure drag for this set of simulations are shown in Fig. 7. A decrease in the critical Richardson number delays the drag amplification and slightly increases the drag value at steady state. The time lag effect is more pronounced in the cases with friction: even after $12 \mathrm{~h}$, simulation 6, corresponding to $\mathrm{Ri}_{c}=0.27$, has not yet reached steady state. Another interesting feature of this figure is the insensitivity of the surface drag to a variation of the convectively unstable mixing length; simulations 3 and 4 give almost identical results. The turbulent kinetic energy fields computed at $12 \mathrm{~h}$ for the simulations 3 to 6 are shown in Fig. 8. Once again, the results are more sensitive to a variation of the stable coefficient ( $C E 5$ or $C K 5$ ) than to a variation of the unstable coefficient ( $C E 1$ or $C K 1$ ). This is consistent with what we saw from the turbulent kinetic energy budget. Most of the energy production occurs through shear production in a convectively stable region. Therefore, the role of the stable coefficient is dominant. Moreover, the turbulence intensity is modulated by the critical Richardson number. The maximum values of the kinetic energy are respectively 117,89 and $65 \mathrm{~m}^{2} \mathrm{~s}^{-2}$ when $\mathrm{Ri}_{c}$ drops from 0.52 to 0.40 and 0.27 . This result seems realistic since a larger $\mathrm{Ri}_{c}$ leads to a stronger develop- ment of the turbulence, and therefore to increased friction at higher levels.

\section{b. Roughness length}

In order to investigate the sensitivity of the flow to roughness length variations, two series of simulations were performed with two different $\mathrm{Ri}_{c}$ values. In each simulation, the roughness length was varied between 10 and $40 \mathrm{~cm}$. The corresponding time evolutions of the surface pressure drag are shown in Fig. 9. For each series an increase in the roughness length delays the drag amplification but has no effect on the steady-state value. A comparison of the two sets of curves $\left(\mathbf{R i}_{c}\right.$ $=0.27$ and $\mathrm{Ri}_{c}=0.52$ ) indicates that the results are less sensitive to roughness variation when turbulence is allowed to live for a longer time. This point may be of some importance. Some additional tests, performed with another type of mixing parameterizations (Blackadar's exchange coefficients of heat and momentum ), showed a much greater sensitivity to a roughness variation. In this case, a roughness length of only $5 \mathrm{~cm}$ completely prevented the drag amplification, and the model results showed a standing gravity wave instead of a downslope windstorm (at least for a $12 \mathrm{~h}$ simulation).

\section{Conclusion}

Our model was able to reproduce the amplification mechanism operating in the 11 January 1972 Boulder windstorm. The agreement obtained between the sim-
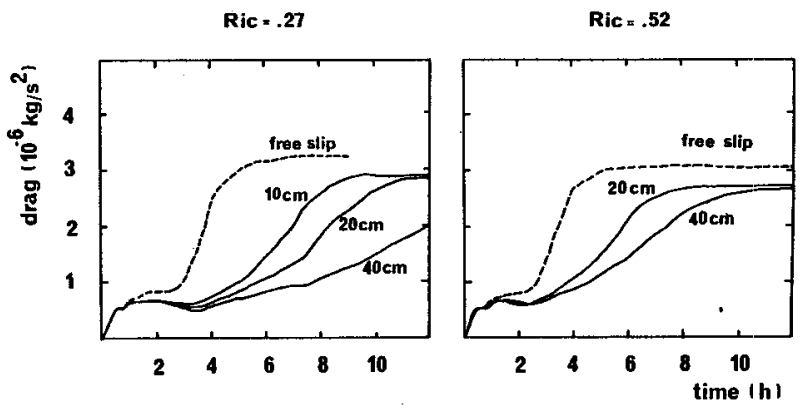

FlG. 7. Time evolutions of the surface pressure drag for different values of $\mathrm{Ri}_{c}$ in case of friction and in case of free slip surface boundary condition. 

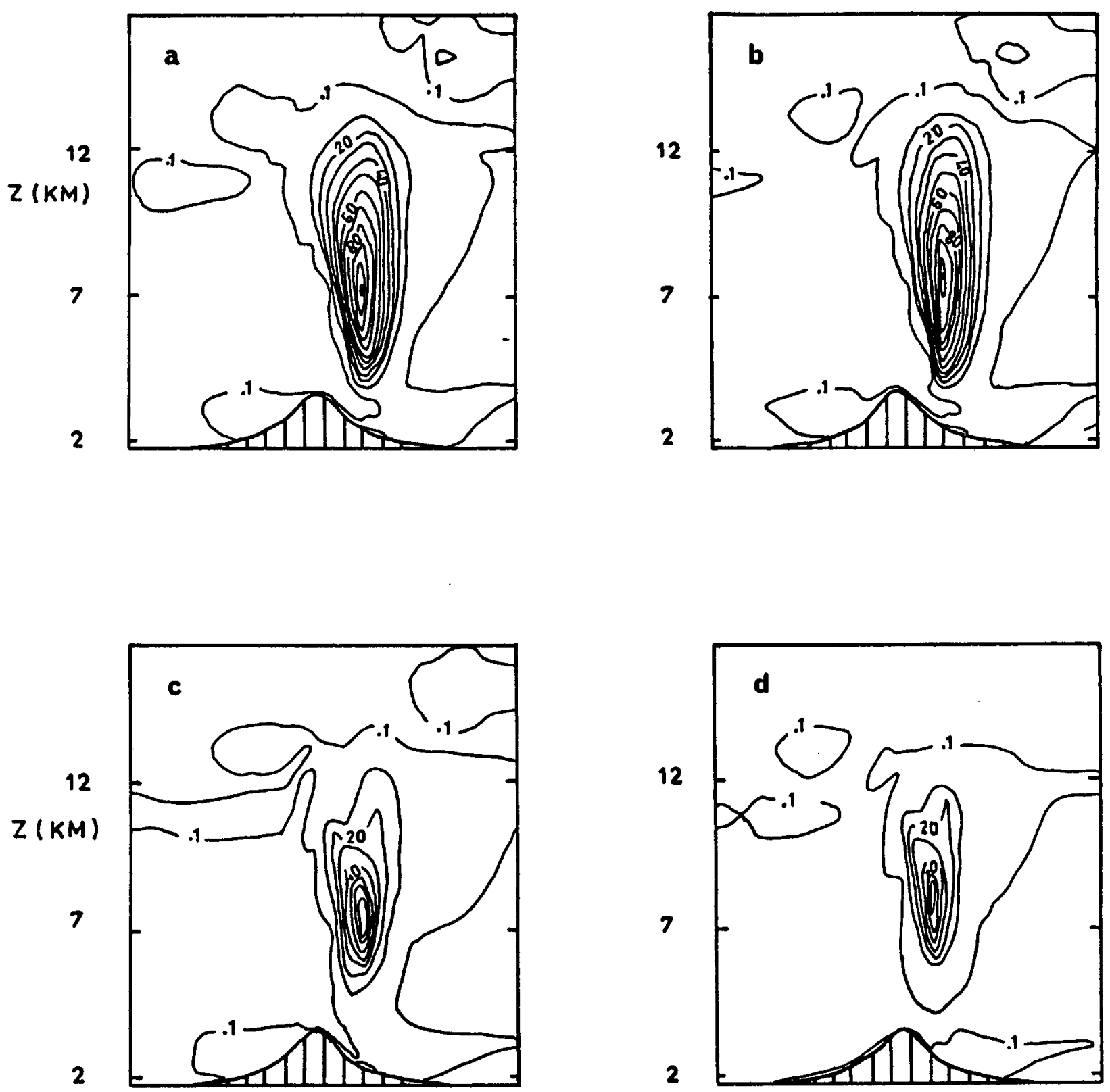

\section{$50 \mathrm{~km}$}

FIG. 8. Vertical cross sections of the turbulent kinetic energy field after $12 \mathrm{~h}$ of integration for the different mixing and dissipation lengths listed in Table 1: (a) simulation 3, (b) simulation 4, (c) simulation 5, (d) simulation 6.

ulations presented here and the referenced nonhydrostatic numerical results indicates that trapped lee waves have no fundamental role in the development of strong downslope winds and high pressure drag (at least for the 11 January 1972 windstorm). Similar results were obtained with the French Weather Service limited-area model Péridot for the $\beta$-mesoscale (Bougeault 1987). These results seem to support the hypothesis of a hydrostatic amplification mechanism due to the transition from subcritical to supercritical flow over the crest of the mountain (Durran 1986; Durran and Klemp 1987). 


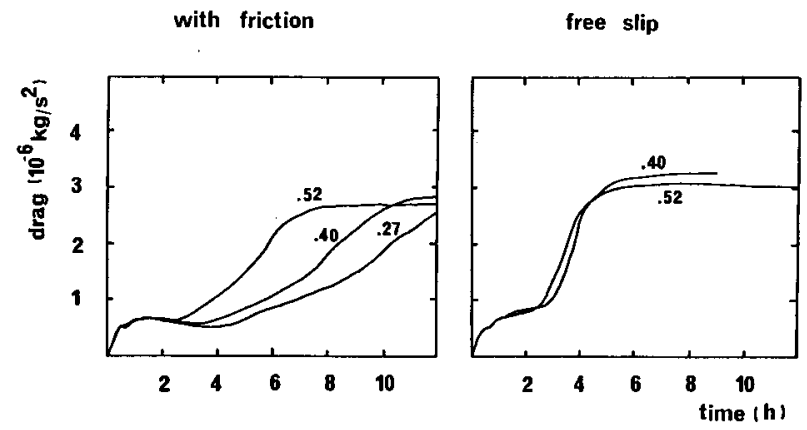

FIG. 9. Time evolutions of the surface pressure drag for different values of $z_{0}$.

The simulations including surface friction effects gave more realistic results than the simulations performed with a bottom free-slip condition. In the cases with friction, the "shooting flow" was confined above the lee slope instead of spreading downwind and the stationary drag value was obtained later; friction was acting against nonlinear advection and slowed the downslope motion.

The turbulent kinetic energy parameterization used in the model gave a fair description of the observed turbulent structure; the turbulence location and intensity were well reproduced, and it was found that the intense midtropospheric turbulence was dominantly shear driven.

The model results showed some sensitivity to the mixing length and roughness length specification. Strong friction was found to delay but never to prevent the development of the downslope windstorm, at least when the TKE parameterization was used. This last result seems rather sensitive to the detailed formulation of the turbulence scheme used. Therefore, it would be very helpful to gather appropriate experimental data including second-order turbulent quantities (TKE, fluxes) in order to validate or improve the present numerical simulations.

Acknowledgments. The authors thank P. Bougeault (CNRM, Toulouse) for very helpful discussions. They also express their sincere appreciation to T. Yamada of Los Alamos National Laboratory for his help and encouragement. This work was supported by grants from Electricité de France. Computer resources were provided by ECWMF (Reading, England), CCVR (Palaiseau, France) and Météorologie Nationale (Paris).

\section{APPENDIX}

\section{List of Principal Symbols}

$B=\frac{g p}{R T \pi \sigma^{\prime}}$ half width of the mountain

vertical scale factor

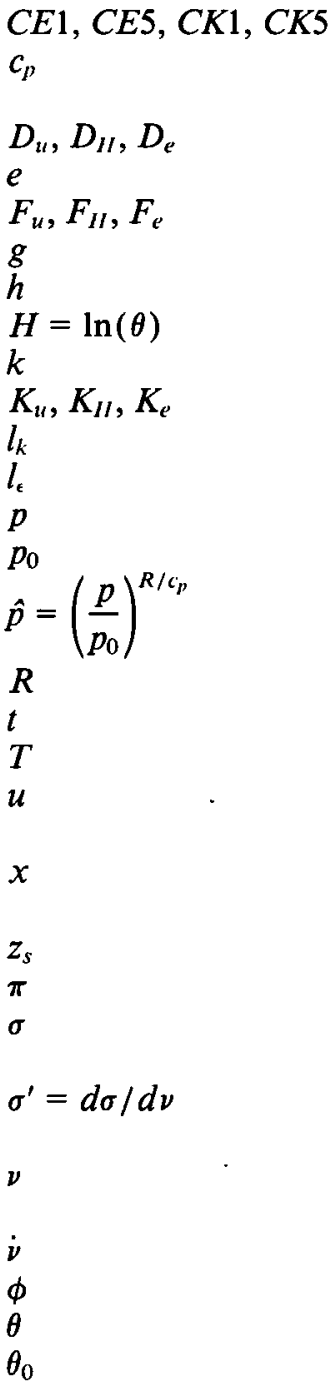

empirical constants specific heat at constant pressure horizontal diffusion terms turbulent kinetic energy vertical diffusion terms acceleration of gravity height of the mountain entropy Von Karman constant exchange coefficients mixing length scale dissipation length scale pressure reference pressure $(1000 \mathrm{hPa})$

Exner function

universal gas constant

time

temperature

horizontal wind speed along the $x$ coordinate

horizontal west-east coordinate

surface height

surface pressure

pressure coordinate defined by $\sigma=p / \pi$

derivative of $\sigma$ with respect to $\nu$

vertical coordinate defined by $\sigma=\nu+0.9 \nu^{2}-0.9 \nu^{3}$

vertical velocity

geopotential

potential temperature

reference potential temperature $(300 \mathrm{~K})$

\section{REFERENCES}

André, J. C., G. De Moor, P. Lacarrère, G. Therry and R. Du Vachat, 1978: Modeling the 24-hour evolution of the mean and turbulent structures of the planetary boundary layer. J. Atmos. Sci., 35, $1861-1883$.

Blackadar, A., 1962: The vertical distribution of wind and turbulent exchange in a neutral atmosphere. J. Geophys. Res., 67, 30953102.

Bougeault, P., 1987: Simulations of orographic flows with a $10 \mathrm{~km}$ scale hydrostatic model. ECWMF workshop on technics for horizontal discretization in NWP models.

Businger, J. A., 1973: Turbulent transfer in the atmospheric surface layer. Workshop on micrometeorology. D. A. Haugen, Ed., Amer. Meteor. Soc., 67-100.

Clark, T. L., and W. R. Peltier, 1977: On the evolution and stability of finite amplitude mountain waves. J. Atmos. Sci., 34, 17151730.

Davies, H. C., 1983: Limitations of some common lateral boundary schemes used in regional NWP models. Mon. Wea. Rev., 111, $1002-1012$.

Durran, D. R., 1986: Another look at downslope winds. Part I: The 
development of analogs to supercritical flow in an infinitely deep, continuously stratified fluid. J. Atmos. Sci., 43, 2527-2543.

- , and J. B. Klemp, 1983: A compressible model for the simulation of moist mountain waves. Mon. Wea. Rev., 111, 2341-2361.

- , and J. B. Klemp, 1987: Another look at downslope winds. Part II: Nonlinear amplification beneath wave-overturning layers. $J$. Atmos. Sci., 22, 3402-3412.

Klemp, J. B., and D. K. Lilly, 1975: The dynamics of wave-induced downslope winds. J. Atmos. Sci., 32, 320-339.

- - and - 1978: Numerical simulation of hydrostatic waves. J. Atmos. Sci., 35, 78-107.

Lilly, D. K., 1978: A severe downslope windstorm and aircraft turbulence event induced by a mountain wave. J. Atmos. Sci., 35, $59-77$.

_ 11, 1972. A meteorological narrative. Weatherwise, 25, 56-63.

- and P. J. Kennedy, 1973: Observations of a stationary mountain wave pattern and its associated momentum flux and energy dissipation. J. Atmos. Sci., 30, 1135-1152.

Louis, J. F., 1979: A parametric model of vertical eddy fluxes in the atmosphere. Bound.-Layer Meteor., 17, 187-202.

Mahfouf, J. F., E. Richard, P. Mascart, E. C. Nickerson and R. Rosset, 1987: A comparative study of various parameterizations of the planetary boundary layer in a numerical mesoscale model. $J$. Climate Appl. Meteor., 26, 1671-1695.

Mahrer, Y., and R. A. Pielke, 1978: A test of an upstream spline interpolation technique for the advective terms in a numerical mesoscale model. Mon. Wea. Rev., 106, 818-830.

Nickerson, E. C., E. Richard, R. Rosset and D. R. Smith, 1986: The numerical simulation of clouds, rain and airflow over the Vosges and Black Forest mountain: a meso- $\beta$ model with parameterized microphysics. Mon. Wea. Rev., 114, 398-414.

Peltier, W. R., and T. L. Clark, 1979: The evolution and stability of finite amplitude mountain waves. Part II: Surface wave drag and severe downslope windstorms. J. Atmos. Sci. 36, 14981529.

Queney, P., 1948: The problem of airflow over mountains. A summary of theoretical studies. Bull. Amer. Meteor. Soc., 16-25.

Smith, R. B., 1977: The steepening of hydrostatic mountain waves. J. Atmos. Sci., 34, 1634-1654.

- 1985: On severe downslope winds. J. Atmos. Sci., 42, 25972603.

Therry, G., and P. Lacarrère, 1983: Improving the eddy kinetic energy model for planetary boundary layer description. Bound.-Layer Meteor., 25, 63-88. 